The aim of the study: To assess the difference of serum level of HE4 and CA125 among patients with endometrioid endometrial cancer, considering the presence or absence of selected risk factors.

Material and methods: A retrospective study of 46 patients, whose serum level of HE4 and CA125 level was documented, admitted to our Clinic because of endometrioid endometrial cancer. The statistical difference of both markers was analyzed considering certain risk factors.

Results: In the examined group of patients there was no significant statistical difference of HE4 and CA125 levels among patients with and without the following risk factors: older age, menopausal status, overweight and obesity, hypertension, diabetes, early menarche, and family history of certain cancers. Similar results were obtained within the subgroup of patients with stage I endometrial cancer. Both HE4 and CA125 were significantly higher in premenopausal patients than in those after menopause in the more advanced stages of the disease. The same results were obtained within group of patients with advanced histological grading G2 and G3. In this group, higher levels of CA125 were observed among patients without hypertension. Among patients with histological grade G1 the serum level of HE4 was higher in the group of patients older than 60 years than it was in younger patients.

Conclusions: In the examined group of patients serum levels of tumour markers may not be affected by the selected risk factors. Higher HE4 and CA125 levels among premenopausal patients may be an alarming sign of advanced stages and classes of histological grading.

Key words: CA125, HE4, endometrial cancer, risk factor, hypertension, menopause.

Contemp Oncol (Pozn) 2016; 20 (6): 463-467 DOI: https://doi.org/10.5114/wo.2016.65606

\section{Analysis of serum level of HE4 and CA125 considering selected risk factors among patients with endometrioid endometrial cancer}

\author{
Nabil Abdalla, Robert Piorkowski, Anna Slomka, Malgorzata Kania, \\ Wlodzimierz Sawicki, Krzysztof Cendrowski
}

Medical University of Warsaw, Warsaw, Poland

\section{Introduction}

Endometrial cancer (EC) is the sixth most common cancer in women worldwide and the fourteenth most common cancer overall [1]. Most of the cases are discovered in the early stages because vaginal bleeding is an early symptom of EC [2]. The most common histological type of EC is the endometrioid [3]. The mortality rate for EC has been increasing more rapidly than the incidence rate. This can be attributed to an increased rate of high-risk histological subtypes, increased rate of advanced stage at the time of diagnosis, and increased number of patients diagnosed at older age [4]. Risk factors for EC include increased age, obesity, long-term exposure to unopposed oestrogens, residence in North America or Europe, high concentration of oestrogens postmenopausally, metabolic syndrome, years of menstruation, nulliparity, long-term use of tamoxifen, hereditary non-polyposis colorectal cancer (HNPCC), hormone replacement therapy with less than 12-14 days of progesterone, and first-degree relative with EC. Decreasing factors include grand multiparity, smoking, oral contraceptive use, physical activity, and diet of some phyto-oestrogens $[5,6]$. Presently no tumour marker is routinely used for diagnosis of EC [2]. Cancer antigen 125 (CA125) has been widely investigated in gynaecological disease; however, its level can be elevated in many malignant and non-malignant gynaecological and other diseases [710]. Human epididymis (HE4) gene was reported for the first time by Kirchhof et al. in 1991 in the epithelial cells of human distal epididymis [11]. HE4 is overexpressed in ovarian cancer. Recently studies have assessed the role of HE4 in the diagnosis, follow-up, and management of EC [3, 4, 12].

\section{Aim of the study}

The aim of the study was to assess the difference between serum levels of tumour markers HE4 and CA125 among patients with endometrioid EC, considering the presence and absence of the following risk factors: older age, early menarche, late menopause, overweight and obesity, diabetes, hypertension, menopause, and family history of certain risk factors. The analysis was planned to be carried out among all patients, groups of patients with certain stages and grading of EC.

\section{Material and methods}

This was a retrospective study of 46 patients diagnosed with endometrioid EC admitted to our clinic between October 2012 and June 2015 for surgical operation. The inclusion criteria were as follows: histological diagnosis of endometrioid EC, a complete history of the patients considering the presence or absence of certain selected risk factors of EC, documented serum level of HE4 and CA125 within one week of surgical operation, and complete 
surgical staging. The following risk factors were considered in the study: age over 60 years, postmenopausal status, overweight and obesity, presence of hypertension, presence of diabetes, early menarche, late menopause, and positive family history of certain cancers. The data of the last menstrual period, height, weight, hypertension, diabetes and family history of a cancer were collected from the histories. The menopause was defined as absence of menstruation for at least one year. The group of malignancies associated with HNPCC are considered in the family history. These include malignancies of the uterus, ovary, breast, gastrointestinal tract, urogenital tract, and prostate [14]. Early menarche was defined as first menstruation before age of 11 years or earlier [15]. Late menopause was defined when menopause occurred at 56 years of age or older [16]. An age over 60 years was used to characterise older patients [17]. Overweight was defined when body mass index (BMI) was equal to or higher than 25 and less than 30. Obesity was defined as BMI equal to or more than 30 [18]. For each patient a blood sample was collected within one week before surgical operation. Both HE4 and CA125 were measured at the same time by kits (Fujirebio Diagnostics, Inc.) in the same apparatus (Cobas 8000 e602) using electro-chemiluminescence immunoassay (ECLIA). Staging of the EC was done according to the International Federation of Gynaecology and Obstetrics (FIGO) [19]. The histological grade of the disease was considered as mild (G1), moderate (G2), or sever (G3) according to the histopathological assessment. Patients with incomplete data, renal diseases, and personal history of malignancy, chemotherapy, or radiotherapy were excluded from the study. The descriptive analysis of the distribution of menopause, hypertension, diabetes, family history of certain cancers, and staging and grading of EC was performed. The Shapiro-Wilk (S-W) test was used to assess the distribution of the variables of HE4 and CA125. Due to lack of normal distribution of the variables of HE4 and CA125, non-parametric U-Mann-Whitney test was used to determine if the serum concentration of tumour markers HE4 and CA125 was significantly higher among patients with selected risk factor than among those without them. The analysis was performed for all stages of EC, stage I, advanced stages of EC, histological $\mathrm{G} 1$, and more advanced grades. In this study a $p$ value less than 0.05 was considered as significant.

\section{Results}

The study involved 46 patients who were diagnosed with endometrioid EC between the ages of 37 and 86 years, with an average age of 66.6 years (standard deviation (SD) $=11.2$ years). The vast majority $42(91.30 \%)$ of patients were after menopause and only 4 (8.7\%) of the patients were before menopause. Menopause occurred at the age of 35 to 59 years, at an average age of 49 years (SD $=5.7$ years). The average age of menarche was 13 years (SD = 1.3 years). The average BMI in the examined patients was $30.4(\mathrm{SD}=7.2)$. The largest group of patients was in stage I (73.91\%). The number of patients with stage II and III was $2(4.35 \%)$ and 10 (21.73\%). Stage IV was not confirmed in any patient. The study included 34 (73.91\%) patients with
G1, nine (19.57\%) patients with G2, and three (6.52\%) patients with G3. Hypertension, diabetes, and family history of certain cancers was confirmed in 28 (60.87\%), eight (17.39\%), and 10 (21.74\%) patients, respectively. The mean level of HE4 was $167.79 \mathrm{pmol} / \mathrm{I}(\mathrm{SD}=238.31)$. The mean level of CA125 was $63.32 \mathrm{U} / \mathrm{ml}(\mathrm{SD}=176.03)$.

The $p$ value for S-W test for both tumour markers was $<0.001$. In the statistical analysis patients were grouped according to the presence of specific risk factors, namely: age above 60 years, postmenopausal status, overweight and obesity, hypertension, diabetes, early menarche, late menopause, and positive family history of certain cancers. The statistical difference in serum concentrations of HE4 and CA125, considering the presence or absence of risk factors, was analysed. A nonparametric U-Mann-Whitney test was performed because the variables were not normally distributed. Results of the statistical analysis considering EC staging and grading are shown in Table 1 and 2, respectively.

Among the whole group of patients and stage I EC patients there was no significant statistical difference of serum concentrations of HE4 and CA125 between groups of patients with specific risk factors and all other examined patients without this risk factor. In the case of advanced stages of EC, premenopausal patients had higher serum concentrations of HE4 and CA125 than postmenopausal patients. Within G1 grade, patients aged over 60 years had higher serum HE4 concentrations than younger patients, while CA125 was not significantly higher. In the advanced histological grades of EC, premenopausal patients had higher levels of HE4 and CA125 than postmenopausal patients. Patients without hypertension had higher CA125 serum concentration levels than patients suffering from this disease.

\section{Discussion}

In our study we assessed the serum levels of HE4 and CA125 in patients with endometrioid EC, considering certain risk factors. In the study of Li et al. the expression rate of HE4 was not significantly different between different histological subtypes of EC [2]. However, Angioli et al. showed a significant difference [20]. In our study patients with histological diagnosis other than endometrioid EC were excluded from the study. The possible effect of significant different levels of HE4 and CA125 among patients with other histological subtypes of EC was eliminated. In the study by Nagy et al. significantly increased HE4 concentrations were found in individuals with decreased glomerular filtration rate compared with a control group. Significant elevation of CA125 was seen only in those who had severe renal failure [21]. In our study the possible false positive results of tumour markers caused by renal diseases were eliminated from the study because all of these patients were excluded from the study. Tamoxifen intake was not taken into consideration in the study because all patients with a previous history of malignancy were excluded from the study.

The prospective study by Brennan et al. of 373 EC patients revealed that HE4 and CA125 were not significantly 
Table 1. Comparison of HE4 and CA125 serum concentrations in patients considering selected risk factors in different stages of EC

\begin{tabular}{|c|c|c|c|c|c|c|c|c|c|c|c|c|c|c|c|c|}
\hline \multirow[t]{3}{*}{ Risk factor } & & \multicolumn{5}{|c|}{ All stages of EC } & \multicolumn{5}{|c|}{ Stage I EC } & \multicolumn{5}{|c|}{ Stages II-III EC } \\
\hline & & \multirow{2}{*}{$\begin{array}{c}N \\
(\%)\end{array}$} & \multicolumn{2}{|c|}{ HE4 } & \multicolumn{2}{|c|}{ CA125 } & \multirow{2}{*}{$\begin{array}{c}N \\
(\%)\end{array}$} & \multicolumn{2}{|c|}{ HE4 } & \multicolumn{2}{|c|}{ CA125 } & \multirow{2}{*}{$\begin{array}{c}N \\
(\%)\end{array}$} & \multicolumn{2}{|c|}{ HE4 } & \multicolumn{2}{|c|}{ CA125 } \\
\hline & & & $M$ & SL & $M$ & SL & & $M$ & SL & $M$ & SL & & $M$ & SL & $M$ & SL \\
\hline \multirow[t]{2}{*}{ Age } & $\begin{array}{l}<60 \\
\text { years }\end{array}$ & $\begin{array}{c}12 \\
(26)\end{array}$ & 82.80 & 0.26 & 15.99 & 0.94 & $\begin{array}{c}8 \\
(23)\end{array}$ & 47.00 & 0.06 & 14.08 & 0.51 & $\begin{array}{c}4 \\
(33)\end{array}$ & 517.8 & 0.68 & 159.3 & 0.28 \\
\hline & $\begin{array}{l}>60 \\
\text { years }\end{array}$ & $\begin{array}{l}34 \\
(74)\end{array}$ & 100.7 & & 20.43 & & $\begin{array}{l}26 \\
(77)\end{array}$ & 94.90 & & 15.85 & & $\begin{array}{c}8 \\
(67)\end{array}$ & 204.15 & & 41.52 & \\
\hline \multirow[t]{2}{*}{ Menopause } & No & $\begin{array}{c}4 \\
(9)\end{array}$ & 460.25 & 0.83 & 104.89 & 0.16 & $\begin{array}{l}2 \\
(6)\end{array}$ & 45.85 & 0.05 & 15.59 & 0.97 & $\begin{array}{c}2 \\
(17)\end{array}$ & 1177.4 & 0.03 & 693.8 & 0.03 \\
\hline & Yes & $\begin{array}{l}42 \\
(91)\end{array}$ & 99.35 & & 18.09 & & $\begin{array}{l}32 \\
(94)\end{array}$ & 94.90 & & 15.72 & & $\begin{array}{l}10 \\
(83)\end{array}$ & 175.15 & & 41.52 & \\
\hline \multirow[t]{2}{*}{ BMI } & $\begin{array}{l}18.5- \\
24,99\end{array}$ & $\begin{array}{c}8 \\
(18)\end{array}$ & 94.90 & 0.35 & 22.65 & 0.21 & $\begin{array}{c}7 \\
(21)\end{array}$ & 93.20 & 0.35 & 22.30 & 0.06 & $\begin{array}{l}1 \\
(9)\end{array}$ & 259.9 & 0.72 & 77.40 & 0.90 \\
\hline & $\geq 25$ & $\begin{array}{l}37 \\
(82)\end{array}$ & 101.30 & & 16.05 & & $\begin{array}{l}27 \\
(79)\end{array}$ & 90.20 & & 11.39 & & $\begin{array}{l}10 \\
(91)\end{array}$ & 202.7 & & 41.52 & \\
\hline \multirow[t]{2}{*}{ Hypertension } & No & $\begin{array}{l}18 \\
(39)\end{array}$ & 112.75 & 0.98 & 20.30 & 0.28 & $\begin{array}{l}12 \\
(35)\end{array}$ & 75.90 & 0.30 & 15.91 & 0.65 & $\begin{array}{c}6 \\
(50)\end{array}$ & 285.75 & 0.18 & 101.2 & 0.31 \\
\hline & Yes & $\begin{array}{l}28 \\
(61)\end{array}$ & 98.25 & & 16.97 & & $\begin{array}{l}22 \\
(65)\end{array}$ & 93.40 & & 13.60 & & $\begin{array}{c}6 \\
(50)\end{array}$ & 148.3 & & 40.86 & \\
\hline \multirow[t]{2}{*}{ Diabetes } & No & $\begin{array}{l}38 \\
(83)\end{array}$ & 98.25 & 0.45 & 18.43 & 0.57 & $\begin{array}{l}28 \\
(82)\end{array}$ & 91.70 & 0.61 & 15.93 & 0.38 & $\begin{array}{l}10 \\
(83)\end{array}$ & 202.7 & 0.75 & 41.52 & 0.75 \\
\hline & Yes & $\begin{array}{c}8 \\
(17)\end{array}$ & 148.80 & & 13.85 & & $\begin{array}{c}6 \\
(18)\end{array}$ & 103.65 & & 9.55 & & $\begin{array}{c}2 \\
(17)\end{array}$ & 218.25 & & 71.72 & \\
\hline \multirow[t]{2}{*}{ Menarche } & Early & $\begin{array}{l}3 \\
(6)\end{array}$ & 100.10 & 0.73 & 26.43 & 0.22 & $\begin{array}{l}2 \\
(6)\end{array}$ & 99.00 & 0.64 & 24.37 & 0.25 & $\begin{array}{c}1 \\
(8)\end{array}$ & 173.7 & 0.83 & 125.0 & 0.66 \\
\hline & Normal & $\begin{array}{l}43 \\
(94)\end{array}$ & 98.60 & & 16.17 & & $\begin{array}{l}32 \\
(94)\end{array}$ & 89.70 & & 15.33 & & $\begin{array}{c}11 \\
(92)\end{array}$ & 231.7 & & 54.00 & \\
\hline \multirow[t]{2}{*}{$\begin{array}{l}\text { Onset of } \\
\text { menopause }\end{array}$} & Normal & $\begin{array}{l}36 \\
(86)\end{array}$ & 97.25 & 0.08 & 16.97 & 0.22 & $\begin{array}{l}29 \\
(91)\end{array}$ & 93.20 & 0.49 & 15.64 & 0.38 & $\begin{array}{c}7 \\
(70)\end{array}$ & 173.7 & 0.26 & 54.00 & 0.83 \\
\hline & Late & $\begin{array}{c}6 \\
(14)\end{array}$ & 174.25 & & 53.22 & & $\begin{array}{l}3 \\
(9)\end{array}$ & 123.5 & & 107.0 & & $\begin{array}{c}3 \\
(30)\end{array}$ & 259.9 & & 29.04 & \\
\hline \multirow{2}{*}{$\begin{array}{l}\text { Positive } \\
\text { family history } \\
\text { of certain } \\
\text { cancers }\end{array}$} & No & $\begin{array}{l}36 \\
(78)\end{array}$ & 100.70 & 0.64 & 18.43 & 0.90 & $\begin{array}{l}26 \\
(77)\end{array}$ & 94.90 & 0.46 & 15.91 & 0.73 & $\begin{array}{l}10 \\
(83)\end{array}$ & 202.7 & 0.36 & 41.52 & 0.27 \\
\hline & Yes & $\begin{array}{l}10 \\
(22)\end{array}$ & 93.90 & & 15.93 & & $\begin{array}{c}8 \\
(23)\end{array}$ & 81.20 & & 13.04 & & $\begin{array}{c}2 \\
(17)\end{array}$ & 834.8 & & 630.02 & \\
\hline
\end{tabular}

EC - endometrial cancer; $N$ - number of patients; $M$ - median; $S L$ - significance level; BMI-body mass index

different considering diabetes and $\mathrm{BMI}$ at a cut-off level of 30 [22]. In spite of different cut-off levels in our study, these results of the prospective study with use of a greater number of patients support our finding. However, our results considering hypertension and age are not compatible with the results of Brennan et al., in which there was a significantly higher level of HE4 among patients with hypertension and patients older than 62 years. Indeed, we found within the group of advanced histological grading G2 and G3 a significantly higher level of CA125 among patients without hypertension than among patients with hypertension. These incompatible results may be related to the smaller number of patients included in our study [22]. Our results are supported by Hsieh et al., who showed no significant statistical difference of CA125 considering age at a cut-off level of 50 years [23]. In our study the serum levels of HE4 and CA125 were not increased significantly in patients with positive family history of certain malignant diseases than in those without family history in all subgroups of patients with endometrioid EC. These results should be interpreted with caution because we included only the possible malignancies related with HNPCC. Further prospective studies are necessary to determine the diagnostic value of HE4 and CA125 in the screening and diagnosis of EC among carriers of HNPCC [14].

Capriglione et al. showed a significantly higher level of HE4 among patients with advanced histological grades [24]. In our study we assessed the statistical difference of serum level of tumour markers among patients with histological grade G1 and among those with G2 and G3. The results are not similar with regard to age, menopausal status, and arterial hypertension. Among patients with histological grade G1, in the group of patients with age $>60$ years a significant higher level of HE4 was found in comparison to patients younger than 60 years. This correlation may 
Table 2. Comparison of HE4 and CA125 serum concentrations considering histological grading

\begin{tabular}{|c|c|c|c|c|c|c|c|c|c|c|c|}
\hline \multirow[t]{3}{*}{ Risk factor } & & \multicolumn{5}{|c|}{ Histological grade G1 } & \multicolumn{5}{|c|}{ Histological grade 2-3 } \\
\hline & & \multirow{2}{*}{$\begin{array}{c}N \\
(\%)\end{array}$} & \multicolumn{2}{|c|}{ HE4 } & \multicolumn{2}{|c|}{ CA125 } & \multirow{2}{*}{$\begin{array}{c}N \\
(\%)\end{array}$} & \multicolumn{2}{|c|}{ HE4 } & \multicolumn{2}{|c|}{ CA125 } \\
\hline & & & $M$ & SL & $M$ & SL & & $M$ & SL & $M$ & SL \\
\hline \multirow[t]{2}{*}{ Age } & $<60$ years & $9(26)$ & 49.00 & 0.03 & 15.80 & 0.56 & $3(25)$ & 861.90 & 0.06 & 193.6 & 0.37 \\
\hline & $>60$ years & $25(74)$ & 96.60 & & 18.56 & & $9(75)$ & 110.8 & & 22.3 & \\
\hline \multirow[t]{2}{*}{ Menopause } & No & $2(6)$ & 45.85 & 0.05 & 15.59 & 0.85 & $2(17)$ & 1177.4 & 0.03 & 693.8 & 0.03 \\
\hline & Yes & $32(94)$ & 94.9 & & 17.17 & & $10(83)$ & 115.4 & & 20.09 & \\
\hline \multirow[t]{2}{*}{ BMI } & $18.5-24.99$ & $6(18)$ & 68.55 & 0.30 & 19.59 & 0.24 & $2(17)$ & 156.55 & 0.75 & 59.3 & 0.75 \\
\hline & $\geq 25$ & $27(82)$ & 90.20 & & 15.01 & & $10(83)$ & 120.5 & & 22.8 & \\
\hline \multirow[t]{2}{*}{ Hypertension } & No & $13(38)$ & 67.7 & 0.15 & 15.64 & 0.88 & $5(42)$ & 311.6 & 0.07 & 96.3 & 0.03 \\
\hline & Yes & $21(62)$ & 96.6 & & 18.56 & & $7(58)$ & 110.8 & & 12.8 & \\
\hline \multirow[t]{2}{*}{ Diabetes } & No & $28(82)$ & 89.7 & 0.159 & 16.11 & 0.94 & $10(83)$ & 166.5 & 0.48 & 28.38 & 0.27 \\
\hline & Yes & $6(18)$ & 197.15 & & 37.66 & & $2(17)$ & 103.65 & & 13.85 & \\
\hline \multirow[t]{2}{*}{ Menarche } & Early & $2(6)$ & 135.8 & 0.47 & 75.72 & 0.10 & $1(8)$ & 100.1 & 0.50 & 22.3 & 0.99 \\
\hline & Normal & 32 (94) & 89.70 & & 15.93 & & $11(92)$ & 121 & & 27.72 & \\
\hline \multirow{2}{*}{$\begin{array}{l}\text { Onset of } \\
\text { menopause }\end{array}$} & Normal & $28(87)$ & 91.7 & 0.23 & 15.93 & 0.18 & $8(80)$ & 115.4 & 0.53 & 20.09 & 0.88 \\
\hline & Late & $4(13)$ & 174.25 & & 92.2 & & $2(20)$ & 206.45 & & 20.92 & \\
\hline \multirow{2}{*}{$\begin{array}{l}\text { Positive } \\
\text { family history } \\
\text { of certain } \\
\text { cancers }\end{array}$} & No & $25(73)$ & 93.2 & 0.67 & 18.29 & 0.70 & $11(92)$ & 120.0 & 0.16 & 22.3 & 0.16 \\
\hline & Yes & $9(27)$ & 89.20 & & 15.8 & & $1(8)$ & 1493.0 & & 1194 & \\
\hline
\end{tabular}

$E C$ - endometrial cancer; $N$ - number of patients; $M$ - median; $S L$ - significance level

indicate the importance of HE4 in the determination of an algorithm for detecting EC in older patients. In the group of patients with advanced histological grading, a significantly higher level of both tumour markers was found in premenopausal patients than in postmenopausal. In addition, a significantly higher level of CA125 was found among patients without hypertension than in the hypertensive patients. This result may implicate the importance of these tumour markers together with age, menopausal state, and hypertension in the future prediction models of EC.

According to some studies in the literature, the serum level of HE4 is significantly higher in advanced stages of EC in comparison to stage I [25]. In stage I of EC, the serum level of tumour markers had no significant statistical difference considering selected risk factors. This may suggest unnecessary use of a correlation between these tumour markers and certain risk factors in the future algorithmic diagnostic methods for early EC. More prospective studies are needed to support our findings. In advanced stages and histological grades of EC, a significantly higher level of HE4 and CA125 was found in premenopausal patients than in postmenopausal. This fact may suggest the importance of the menopausal status in establishing algorithms for EC in the future.

The strength of our study includes the fact that only endometrioid EC patients were taken into consideration, making the group homogenous. Serum levels of HE4 and CA125 were measured together within one week before surgical operation using the same protocol. All patients with renal diseases were excluded from the study. The weakness of the study is the retrospective type of the study and the small total number of patients included in the study. One of the weak points in our study is the overlapping of risk factors. One patient may have multiple risk factors. Indeed, some risk factors often occur together. For example, metabolic syndrome is a constellation of interconnected physiological, biochemical, clinical, and metabolic factors that predispose to cardiovascular diseases, hypertension, diabetes, and dyslipidaemia [26]. The presence of certain individual risk factors in this syndrome may contribute to the increased level of tumour markers, making the interpretation of the overall result invalid. Studies with certain groups of risk factors can be an option when these risk factors coexist. Our study was conducted only in one centre. Further prospective multicentre studies are needed to support our findings.

The results of our study need to be validated by studies comparing the differences of the serum level of these tumor markers considering certain risk factors between EC patients and control patients. These risk factors alone may affect the serum level of these markers. Higher levels of HE4 are related to age, smoking, and hepatic and renal failure while lower levels of HE4 are related to obesity [25]. The study of Bolstad et al. revealed that age was the main determinant of HE4 level among healthy subjects, and it increases with increasing age [27].

HE4 and CA125 can be used with clinical data for the prediction for risk of ovarian malignancy [28]. Our findings may give impulse for the development of algorithmic models considering HE4 and CA125 with other clinical data including risk factors for prediction of high-risk patients to select the most appropriate method of management. 
In conclusions:

1. There is a limited value to correlate the level of HE4 and CA125 with certain risk factors among the group of all patients with endometrioid endometrial cancer and the subgroup of patients with stage I.

2. Higher levels of HE4 and CA125 may be an alarming sign among premenopausal patients with advanced stages and classes of histological grading of endometrial cancer.

3. Elevated CA125 may be used in future in algorithms for prediction of high-grade endometrial cancer in patients without hypertension.

This study was supported by grant project of Medical University of Warsaw for research and scientific work aimed at scientific development of young doctors and PhD students (Nr 2WA/PM22D/15).

The authors declare no conflict of interest.

\section{References}

1. Ferlay J, Soerjomataram I, Ervik M, Dikshit R, Eser S, Mathers C, Rebelo M, Parkin DM, Forman D, Bray, F. GLOBOCAN 2012 v1.1, Cancer Incidence and Mortality Worldwide: IARC CancerBase No. 11 [Internet]. Lyon, France: International Agency for Research on Cancer; 2014. Available from: http://globocan.iarc.fr, accessed on $16 / 01 / 2015$

2. Li X, Gao Y, Tan M, Zhuang H, Gao J, Hu Z, Wang H, Zhu L, Liu J, Lin B. Expression of HE4 in Endometrial Cancer and Its Clinical Significance. Biomed Res Int 2015; 2015: 437468.

3. Nofech-Mozes S, Ghorab Z, Ismiil N, Ackerman I, Thomas G, Barbera L, Covens A, Khalifa MA. Endometrial endometrioid adenocarcinoma: a pathologic analysis of 827 consecutive cases. Am J Clin Pathol 2008; 129: 110-4.

4. Angioli R, Capriglione S, Scaletta G, Aloisi A, Miranda A, De Cicco Nardone C, Terranova C, Plotti F. The role of HE4 in endometrial cancer recurrence: how to choose the optimal follow-up program. Tumour Biol 2016; 37: 4973-8.

5. Amant F, Moerman P, Neven P, Timmerman D, Van Limbergen E, Vergote I. Endometrial cancer. Lancet 2005; 366: 491-505.

6. Xu WH, Xiang YB, Ruan ZX, Zheng W, Cheng JR, Dai Q, Gao YT, Shu $X O$. Menstrual and reproductive factors and endometrial cancer risk: Results from a population-based case-control study in urban Shanghai. Int J Cancer 2004; 108: 613-9.

7. Meden H, Fattahi-Meibodi A. CA 125 in benign gynecological conditions. Int J Biol Markers 1998; 13: 231-7.

8. Park Y, Lee JH, Hong DJ, Lee EY, Kim HS. Diagnostic performances of HE4 and CA125 for the detection of ovarian cancer from patients with various gynecologic and non-gynecologic diseases. Clin Biochem 2011; 44: 884-8

9. Coppolino G, Bolignano D, Rivoli L, Mazza G, Presta P, Fuiano G. Tu mour markers and kidney function: a systematic review. Biomed Res Int 2014; 2014: 647541.

10. Wang L, Zhan C, Zhang Y, Ma J, Xi J, Jiang W, Shi Y, Wang Q. Quanti fying the expression of tumor marker genes in lung squamous cell cancer with RNA sequencing. J Thorac Dis 2014; 6: 1380-7.

11. Kirchhoff C, Habben I, Ivell R, Krull N. A major human epididy mis-specific cDNA encodes a proteinwith sequence homology to extracellular proteinase inhibitors. Biol Reprod 1991; 45: 350-7.

12. Liu X, Zhao F, Hu L, Sun Y. Value of detection of serum human epididymis secretory protein 4 and carbohydrate antigen 125 in diagnosis of early endometrial cancer of different pathological subtypes. Onco Targets Ther 2015; 8: 1239-43.

13. Dobrzycka B, Mackowiak-Matejczyk B, Terlikowska KM, Kinalski M, Terlikowski SJ. Utility of HE4 to identify patients with endometrioid endometrial cancer who may require lymphadenectomy. Adv Med Sci 2015; 61: 23-7.
14. Dębniak T, Gromowski T, Scott RJ, Gronwald J, Huzarski T, Byrski T, KurzawskiG, Dymerska D, GórskiB, Paszkowska-SzczurK, CybulskiC, Serrano-Fernandez P, Lubiński J. Management of ovarian and endometrial cancers in women belonging to HNPCC carrier families: review of the literature and results of cancer risk assessment in Polish HNPCC families. Hered Cancer Clin Pract 2015; 13: 3.

15. Nnoaham KE, Webster P, Kumbang J, Kennedy SH, Zondervan KT. IS early age at menarche a risk factor for endometriosis? A systematic review and meta-analysis of case-control studies. Fertil Steril 2012; 98: 702-12

16. Menopause: Overview. Eunice Kennedy Shriver National Institute of Child Health and Human Development. 2013-06-28. Retrieved 8 March 2015.

17. World Health Organization. Definition of an older or elderly person. http://www.who.int/healthinfo/survey/ageingdefnolder/en/ (Access: 2016.02.28)

18. World Health Organization. Mean Vody Mass Index (BMI). http:// www.who.int/gho/ncd/risk_factors/bmi_text/en/ (Access: 2016. 02.28).

19. Pecorelli S. Revised FIGO staging for carcinoma of the vulva, cervix, and endometrium. Int J Gynaecol Obstet 2009; 105: 103-4

20. Angioli R, Plotti F, Capriglione S, Montera R, Damiani P, Ricciardi R, Aloisi A, Luvero D, Cafà EV, Dugo N, Angelucci M, Benedetti-Panici P. The role of novel biomarker HE4 in endometrial cancer: a case control prospective study. Tumour Biol 2013; 34: 571-6.

21. Nagy B Jr, Krasznai ZT, Balla H, Csobán M, Antal-Szalmás P, Hernádi Z, Kappelmayer J. Elevated human epididymis protein 4 concentrations in chronic kidney disease. Ann Clin Biochem 2012; 49 (Pt 4): 377-80.

22. Brennan DJ, Hackethal A, Metcalf AM, Coward J, Ferguson K, Oehler MK, Quinn MA, Janda M, Leung Y, Freemantle M; ANECS Group, Webb PM, Spurdle AB, Obermair A. Serum HE4 as a prognostic marker in endometrial cancer--a population based study. Gynecol Oncol 2014; 132: 159-65.

23. Hsieh $\mathrm{CH}$, ChangChien CC, Lin H, Huang EY, Huang CC, Lan KC, Chang SY. Can a preoperative CA 125 level be a criterion for full pelvic lymphadenectomy in surgical staging of endometrial cancer? Gynecol Oncol 2002; 86: 28-33.

24. Capriglione S, Plotti F, Miranda A, Ricciardi R, Scaletta G, Aloisi A, Guzzo F, Montera R, Angioli R. Utility of tumor marker HE4 as prognostic factor in endometrial cancer: a single-center controlled study. Tumour Biol 2015; 36: 4151-6.

25. Minar L, Klabenesova I, Jandakova E, Zlamal F, Bienertova-Vasku J. Prognostic value of human epididymis protein 4 in endometrial cancer and its utility for surgical staging. J Obstet Gynaecol Res 2015; 41: 1644-52.

26. Kaur J. A comprehensive review on metabolic syndrome. Cardiol Res Pract 2014; 2014: 943162.

27. Bolstad N, Øijordsbakken M, Nustad K, Bjerner J. Human epididymis protein 4 reference limits and natural variation in a Nordic reference population. Tumour Biol 2012; 33: 141-8.

28. Michalak M, Gasiorowska E, Nowak Markwitz E. Diagnostic value of CA125, HE4, ROMA and logistic regression model in pelvic mass diagnostics - our experience. Ginekol Pol 2015; 68: 256-61.

\section{Address for correspondence}

\section{Nabil Abdalla}

Chair and Clinic of Obstetrics, Gynecology and Oncology

Second Faculty of Medicine

Medical University of Warsaw

Kondratowicza 8

03-242 Warsaw, Poland

tel./fax +482232653 80,

e-mail:drnabilabdalla@yahoo.com

Submitted: 5.05 .2016

Accepted: 7.11.2016 